\title{
Health Education Barriers, Encountered by Nurses at Oral Healthcare units.
}

\author{
Abd El Azize Th ${ }^{1}$. M. Ibrahim AF ${ }^{2 *}$. \\ ${ }^{l}$ Medical Surgical Department, Faculty of Nursing, Alexandria University. Egypt \\ ${ }^{2}$ Nursing Education Department, Faculty of Nursing, Alexandria University. Egypt
}

\begin{abstract}
World-wide accepted methods for prevention and management of oral health problems are the health education messages. Expert health educators are required with appropriate knowledge, skills related to the recognition, diagnosis, caring and referral for patients with oral health complains. Nurses are facing multiple difficulties when assuming health education activities with dental patients. Therefore, this is a descriptive study, aimed to determine the health education barriers encountered by nurses at oral healthcare units. The study was conducted at the two major oral health settings in Alexandria namely; Alexandria Dental Research Center at Smoha and Free dental and oral clinic in El Amery University hospital. Convenient sample comprised of 125 nurses; 35 from Alexandria Dental Research Center at Smoha and 70 from free dental and oral clinic in El Amery University hospital. Health Education Barriers Questionnaire (HEBQ) was used to collect the necessary data of the study which was developed by Abd El Mohsen in 2009 and modified by the researchers. Based on the analysis of the subject's responses, the results revealed that: the nurses at oral health units have a serious lack in knowledge regarding health education process and there are several barriers and difficulties faced them in providing oral health education related to themselves such as limited communication skills and lack of time. For barriers in patients: there were health beliefs and decreased level of education. For health setting and staff, there is no suitable place for health education, increase work load and staff shortage. The major recommendation of present study is to develop an oral health education strategic plan for nurses to help them; managing any obstacles may face them in oral health education.
\end{abstract}

Key words: Oral health education, Barriers, Nurses

\section{Introduction}

Oral health problems, require a great informational help, to support patients' managing the variety of oral health complains as tooth loss, dental caries, periodontal diseases, oral mucosal diseases as candidiasis and even dangerous diseases as squamous cell carcinoma. (Hmud R., Walsh LJ. 2009 and Mayeaux EJ et al., 1996) Moreover, complications of systemic diseases and its treatments side effects are frequently affecting salivary mechanism, oral motor, and oral sensory functions that need proper health awareness. Therefore, in some dental cases, health teaching is considering the total care. Patient education in oral health care will improve and stabilize individuals' oral health status and general health as well. (Mayeaux EJ et al., 1996 and (Shay K, Ship JA 1995)

The nurse as a health educator in oral health field should be aware with update knowledge and orient by the educational, communicational, and social processes to establish suitable patient health education interventions. Nurses should be well prepared to enter the profession as role models and cleverer guide in the health education field. (Hmud R., Walsh LJ. 2009 and Abd El Mohsen A 2009)

Study significance: Among Nurses; there are several barriers and difficulties that have been proposed for the explanation of the discrepancy between expectation and practice of health education as: time constraints, lack of well-defined role expectation, lack of communication skills or resources and lack of effective health education courses. Other barriers rose from patients and their families, health setting and surrounding staff. Despite the efforts for nursing staff education and training, patient education remains inconsistent and minimally effective. (Fathy A. 2006, University of Wales Swansea 1999 Abd El Mohsen A 2009)

Significance: Sometimes, only health education is enough to manage oral health 
problems among patients. Therefore, identifying the barriers that encountered nurses in providing patient education, especially in oral health care, would be a beneficial step to avoid it and enhance the quality of oral and dental care services. This study aimed to determine the health education barriers encountered by nurses at oral healthcare units.

\section{Material and Method:}

\section{Research design:}

A descriptive research design.

\section{Setting:}

The study was conducted at the following setting: Alexandria Dental Research Center at Smoha and Free dental and oral clinic in El Amery University hospital.

\section{Subjects}

A convenient sample included 125 nurses who accepted to participate and was present at the time of data collection in the previous mentioned settings. 35 from Alexandria Dental Research Center at Smoha and 70 from free dental and oral clinic in El Amery University hospital. They mostly enrolled at morning and evening shifts.

\section{Tool for data collection}

Health Education Barriers Questionnaire (HEBQ) was used for data collection. It was developed by Abd El Mohsen in 2009 and modified by the researchers. This tool includes statements to determine the hindering factors, problems and difficulties that encountered by nurses while providing patient health education. Reliability of the tool was tested using Cronbach Alpha Coefficient test, its value is (0.72 to 0.81$)$. Questions were a form of MCQ with 3, 4, 5 or 6 alternatives. The correct answer took the highest score.

\section{Methods}

The study was executed according to the following steps: Official Permission to conduct this study was obtained from the study settings. Written consent was obtained from the subjects.

Tool was modified after extensive reviewing of relevant and current literature. Content validity of the tool was tested by a jury of seven experts in the related field and necessary modifications were done.

A pilot study was carried out on 15 nurses apart of the study sample. The study tool was distributed on study participants during morning and evening shifts, in the presence of the researcher for any clarifications.

\section{Statistical analysis:}

Data was fed, coded, edited and analyzed using PC with statistical packages for social science (SPSS, 19) version 7.0 for windows. The selected level of significance was $\mathrm{P} \leq 0.05$. The results were estimated using numbers, percentage, arithmetic mean, standard deviation and median. Analytical statistics were done using Chi-square T, ANOVA tests.

3. Results have been clarified as follows:

a) Subjects' characteristics

Table (1) shows the percent distribution of the subjects according their general characteristics. More than half $(56 \%)$ of the subjects were in early twenties. The majority $(81.6 \%)$ of them were females and nearly two-thirds (60\%) were from Urban areas. More than two-thirds $(68 \%)$ of the subjects had diploma certificate from nursing, polymeric or commercial diploma school. Also, More than two-thirds $(65 \%)$ of them had around 5 to 10 years of experience in oral health care. The majority $(80 \%)$ had no previous studies about health education.

Table (1): Percent distribution of the subjects according to their general characteristics.

\begin{tabular}{|c|c|c|c|}
\hline General characteristics & $\begin{array}{c}\text { No } \\
\mathrm{N}=125 \\
\end{array}$ & & \\
\hline $\begin{array}{l}\text { Age: } \\
-18 \leq 25 \\
-25 \leq 35 \\
-35 \leq 45 \\
-45 \leq 55\end{array}$ & $\begin{array}{l}70 \\
25 \\
10 \\
20\end{array}$ & $\begin{array}{c}56 \\
8\end{array}$ & $\begin{array}{c}20 \\
16\end{array}$ \\
\hline
\end{tabular}


Abd El Azize Th1. M. Ibrahim AF2 ${ }^{*}$." Relationship betw ..."

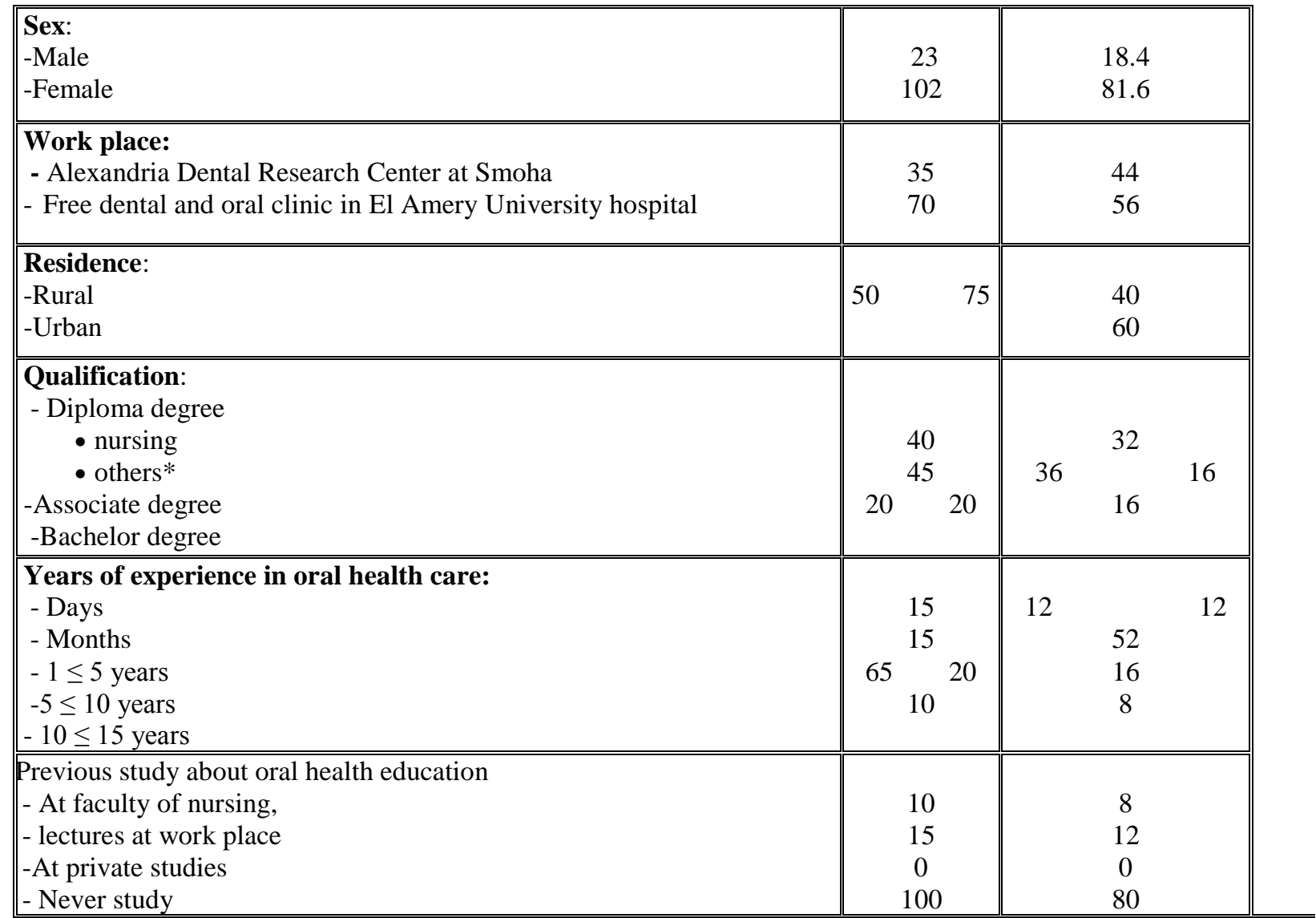

\section{*= Polymeric or commercial diploma}

\section{b) Barriers in health education process:}

According to data in table (2), the majority (82.4\%) of the nurses was interested to work in oral health field but more three quarters $(78.4 \%)$ of them had no time to communicate health messages with patients. About two third of them (72\%) didn't know the importance of oral care health education and approximately two third $(60.8 \%)$ perceived that there is no specific responsible person to provide health education in oral health units.

Nearly three quarters (72\%) of subjects didn't know to take patient approval before teaching and the same proportion didn't identify the value of health education for patient. Almost all of the nurses $(40 \%$ and $54.4 \%$ ) perceived that they had limited and no knowledge about health education assessment.

The majority of the subjects $(80 \%)$ didn't identify how to assess patient knowledge before teaching and about the same percent $(78.4 \%)$ didn't know the methods of data collection in health education assessment. The most apparent barrier regarding assessment in oral care health education was the lake of knowledge about this process in general that mentioned by $44 \%$ of the nurses and lack of communication skills which reported by $32 \%$ of them.

Table (3) reveals that almost all (89.6\% and 92\%) of the nurses reported that they didn't know to plan for oral health education or to write the educational objectives while, $80 \%$ of them mentioned that they can prepare the content of oral health education. $36 \%$ and $36 \%$ of the nurses reported that the most common two barriers regarding planning for health education were the difficulty of language of health messages and there was no enough time to prepare the teaching content.

\begin{tabular}{|c|c|c|}
\hline Difficulties in health education knowledge $\&$ assessment & $\begin{array}{c}\text { No. } \\
\mathrm{N}=125\end{array}$ & $\%$ \\
\hline $\begin{array}{l}\text { Interesting in oral health care work: } \\
- \text { Yes } \\
\text {-No }\end{array}$ & $\begin{array}{c}103 \\
22\end{array}$ & $\begin{array}{l}82.4 \\
17.6\end{array}$ \\
\hline
\end{tabular}


Abd El Azize Th1. M. Ibrahim AF2"." Relationship betw ..."

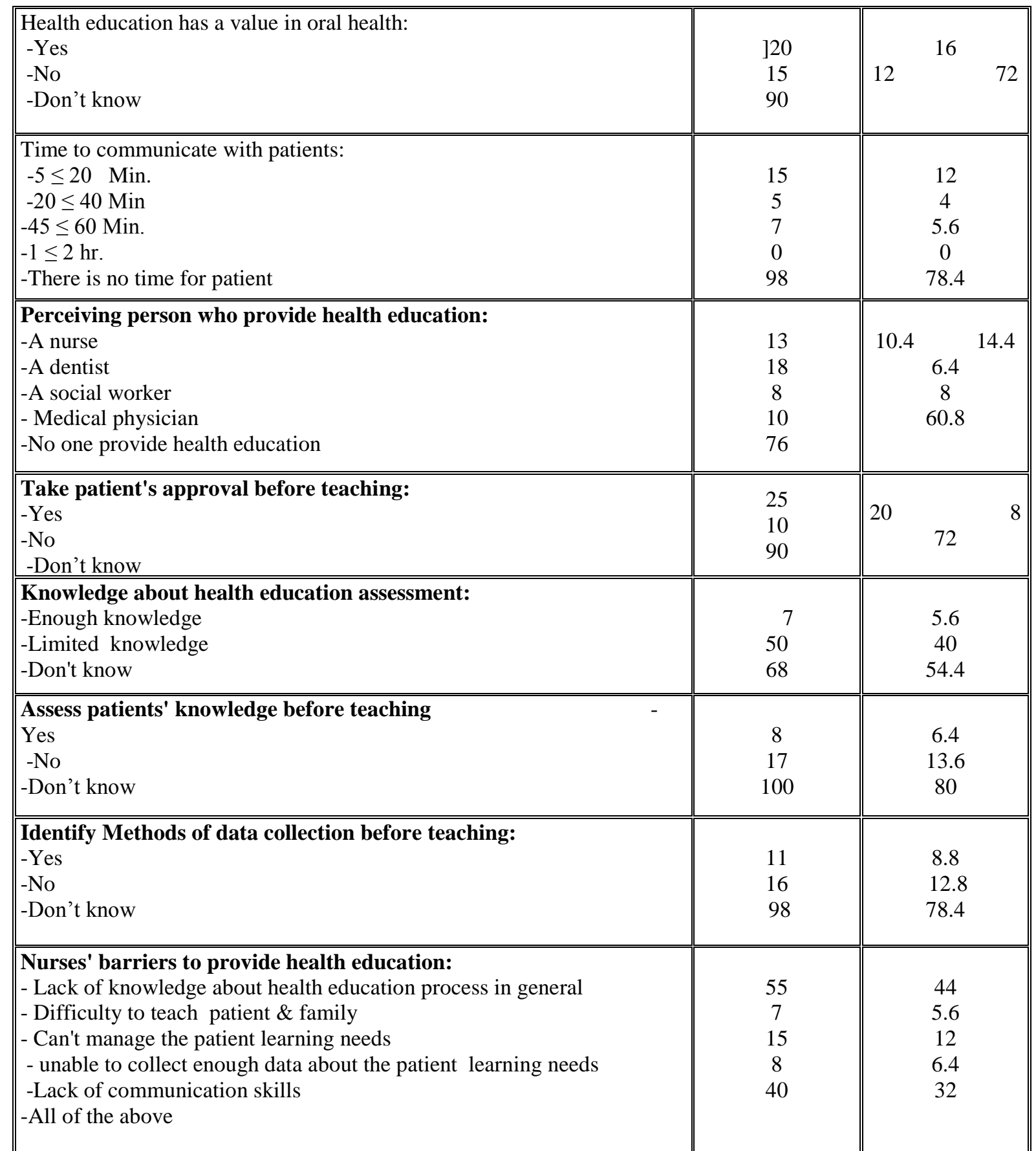

More than one half (56\%) of the subjects didn't know how to prepare audiovisuals for oral health education and about the same proportion $(52 \%)$ of them didn't know the types of audiovisuals. $56 \%$ of the nurses mentioned that, the most apparent barrier related to develop of audiovisuals was; there is no enough time for preparing and designing it. Table (4) shows, that the majority of nurses $(81.6 \%)$ didn't provide clarifications and examples for patients and about three quarters $(72 \%)$ didn't provide motivation and recognition during oral care health education. All subjects $(56 \%, 44 \%)$ have no knowledge about methods of teaching in health education. The majority $(76 \%$ and $80 \%)$ of the nurses didn't evaluate patients' learning and teaching effectiveness while about the same proportion $(81.6 \%)$ of them were recording patient teaching activities. Less than two thirds $(60 \%)$ of nurses fount that difficulty in formulating questions was the apparent barrier in evaluation of oral health education while regarding documentation of health education, $36 \%$ and $56 \%$ of them reported that there was no specific document for recording health education activities and also, there was no enough time for recording.

c) Patients' factors: Respectively to the factors of the patients that may perceived as oral health education barriers by the study subjects, in figure (1) clarifies that almost all 
(86.4 and 74.4) of nurses mentioned that health beliefs or thoughts and patients' level of education were the major factors that hindered oral health education, followed by patients' past experience, religion and language.

According to data in table (5) More than one half $(60 \%)$ of the nurses complained that there was un-cooperation from patients and their families. Respectively proportions $(48 \%$ and $36 \%$ ) of the subjects found that gingival and psychological problems were the most common difficulties that hinder oral care health education, while, near two third of them $(60.8 \%)$ found that headache was the apparent patients' complain that affect oral health education. Lack of patients' trust on a nurse as a source of information was the most common barrier related to patient and family which reported by $52 \%$ of subjects.

\section{d) Health team and setting:}

In relation to barriers with health team and setting, table (6) shows that, nearly two thirds $(64 \%)$ of the subjects found that the health team was always cooperated, but $(36 \%$ and $48 \%$ ) of them mentioned that there was no suitable place to conduct oral health education. respectively, about three quarters $(71.2 \%)$ of the nurses complained that rules, routine and polices of the health setting considered barriers to implement oral care health education activities, and almost of them $(81 \%)$ reported that there are no availability of resources for health education. The work overload in the unit was the most apparent barrier that reported by about two third (68\%) of the nurses.

Table (7) reveals that there was no statistical significance difference between male and female subjects in relation to the all revealed barriers in oral care health education $(\mathrm{T}=0.826$ \& $\mathrm{P}=0.205$ for barriers in conducting the process of health education, $\mathrm{T}=0.774 \& \mathrm{P}=$ 0.44 for barriers in patients and their families, $\mathrm{T}=0.273 \& \mathrm{P}=0.392$ for barriers in health team and setting) Both sexes approximately, confront all types of barriers by the same proportion.

According to data in table (8), it was observed that there was a strong statistical significance difference between diploma, associate and bachelor degrees in favor of diploma nurses in relation to all revealed barriers. All barriers increased among diploma nurses (as mean values are increased) than bachelor and associate nurses in relation to the process of health education $(\mathrm{F}=81.122)$, patient and family $(\mathrm{F}=76.25)$, and health team and setting $(\mathrm{F}=49.65)$.

As observed in table (9) the study subjects ranked the health education barriers as follows; Barriers in relation to conducting the health education process as the first and major difficulty (Median $=3.00$ ) followed by health team \& health setting barriers (Median $=2.00$ ), then barriers regarding patients and families $\begin{array}{llll}\text { Median } & = & 1.00\end{array}$

Table (3): Distribution of the subjects according to their difficulties in oral care health education planning.

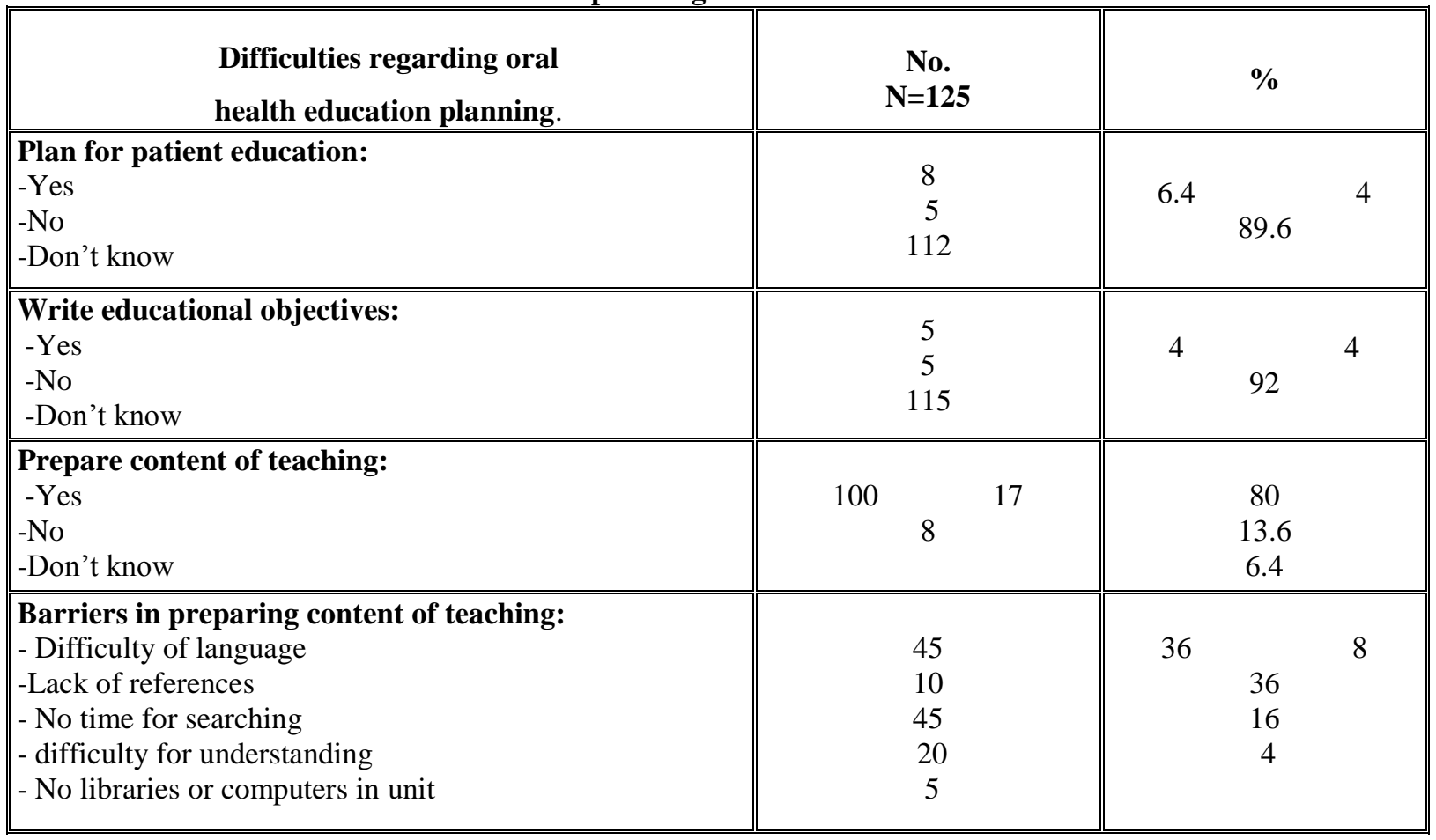


Abd El Azize Th1. M. Ibrahim AF2 ${ }^{*}$." Relationship betw ..."

\begin{tabular}{|c|c|c|c|c|c|c|}
\hline $\begin{array}{l}\text { Prepare audiovisuals: } \\
\text {-Yes } \\
\text {-No } \\
\text {-Don't know }\end{array}$ & 7 & 70 & 48 & & $\begin{array}{c}5.6 \\
38.4 \\
56\end{array}$ & \\
\hline $\begin{array}{l}\text { Knowledge about audiovisuals types: } \\
\text {-Good knowledge } \\
\text {-Limited knowledge } \\
\text {-Don't know }\end{array}$ & 10 & 65 & 50 & 8 & 52 & 40 \\
\hline $\begin{array}{l}\text { Barriers in preparing audiovisuals: } \\
\text { - Difficulty to select suitable one } \\
\text { - difficulty of health topics } \\
\text {-Lack of references } \\
\text { - No time for designing } \\
\text { - Expensive of the materials understanding }\end{array}$ & & $\begin{array}{c}25 \\
10 \\
15 \\
70 \\
5\end{array}$ & & 20 & $\begin{array}{c}12 \\
56 \\
4\end{array}$ & 8 \\
\hline
\end{tabular}

Table (4): Distribution of the subjects according to their difficulties in oral health education conduction, evaluation and documentation.

\begin{tabular}{|c|c|c|}
\hline $\begin{array}{l}\text { Difficulties regarding oral health education conduction, } \\
\text { evaluation } \& \text { documentation. }\end{array}$ & $\begin{array}{c}\text { No. } \\
\mathrm{N}=125\end{array}$ & $\%$ \\
\hline $\begin{array}{l}\text { Provide clarifications \& examples for patient: } \\
\text {-Yes } \\
\text {-No } \\
\text {-Don't know } \\
\end{array}$ & $\begin{array}{c}20 \\
102 \\
3 \\
\end{array}$ & $\begin{array}{c}16 \\
81.6 \\
2.4\end{array}$ \\
\hline $\begin{array}{l}\text { Provide motivation \& recognition for patient: } \\
\text {-Yes } \\
\text {-No } \\
\text {-Don't know } \\
\end{array}$ & $\begin{array}{l}25 \\
10 \\
90 \\
\end{array}$ & $\begin{array}{c}20 \\
8 \\
72 \\
\end{array}$ \\
\hline $\begin{array}{l}\text { Identify methods of teaching in health education: } \\
\text {-Yes } \\
\text {-No } \\
\text {-Don't know }\end{array}$ & $\begin{array}{c}0 \\
70 \\
55\end{array}$ & $\begin{array}{c}0 \\
56 \\
44\end{array}$ \\
\hline $\begin{array}{l}\text { Evaluate patient learning: } \\
\text {-Yes } \\
\text {-No } \\
\text {-Don't know } \\
\end{array}$ & $\begin{array}{c}10 \\
20 \\
95 \\
\end{array}$ & $\begin{array}{c}8 \\
16 \\
76 \\
\end{array}$ \\
\hline $\begin{array}{l}\text { Evaluate teaching effectiveness: } \\
\text {-Yes } \\
\text {-No } \\
\text {-Don't know } \\
\end{array}$ & $\begin{array}{c}17 \\
8 \\
100 \\
\end{array}$ & $\begin{array}{c}13.6 \\
6.4 \\
80 \\
\end{array}$ \\
\hline $\begin{array}{l}\text { Recording health education activities: } \\
\text {-Yes } \\
\text {-No } \\
\text {-Don't know } \\
\end{array}$ & $\begin{array}{c}102 \\
20 \\
3 \\
\end{array}$ & $\begin{array}{c}81.6 \\
16 \\
2.4 \\
\end{array}$ \\
\hline $\begin{array}{l}\text { Barriers in evaluation of patient education: } \\
\text { - Difficulty to prepare questions } \\
\text { - Lack of knowledge about evaluation tools } \\
\text {-Lack of references } \\
\text { - No time for evaluation }\end{array}$ & $\begin{array}{l}75 \\
10 \\
15 \\
25\end{array}$ & $\begin{array}{r}60 \\
8 \\
12 \\
20\end{array}$ \\
\hline $\begin{array}{l}\text { Barriers in recording of patient education: } \\
\text { - no specific document for health teaching activities. } \\
\text {-Lack of knowledge about documentation } \\
\text { - Lack of rules to guide recording } \\
\text { - No time for documentation }\end{array}$ & $\begin{array}{c}45 \\
6 \\
4 \\
70\end{array}$ & $\begin{array}{l}36 \\
4.8 \\
3.2 \\
56\end{array}$ \\
\hline
\end{tabular}




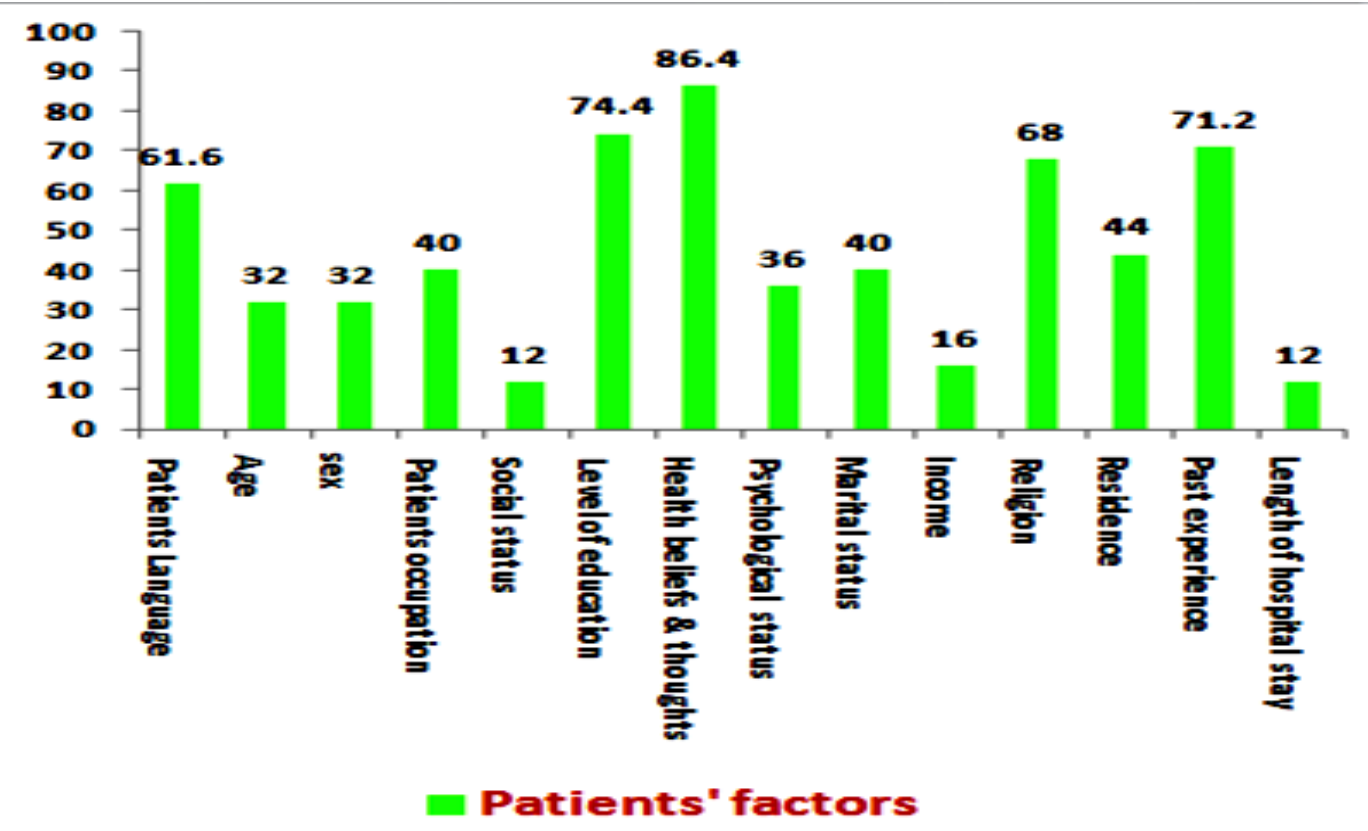

Figure 1: Distribution of patients' characteristics as health education barriers as perceived by the study subjects.

Table (5): Distribution of the subjects according to their perceived patients and families difficulties in oral care health education.

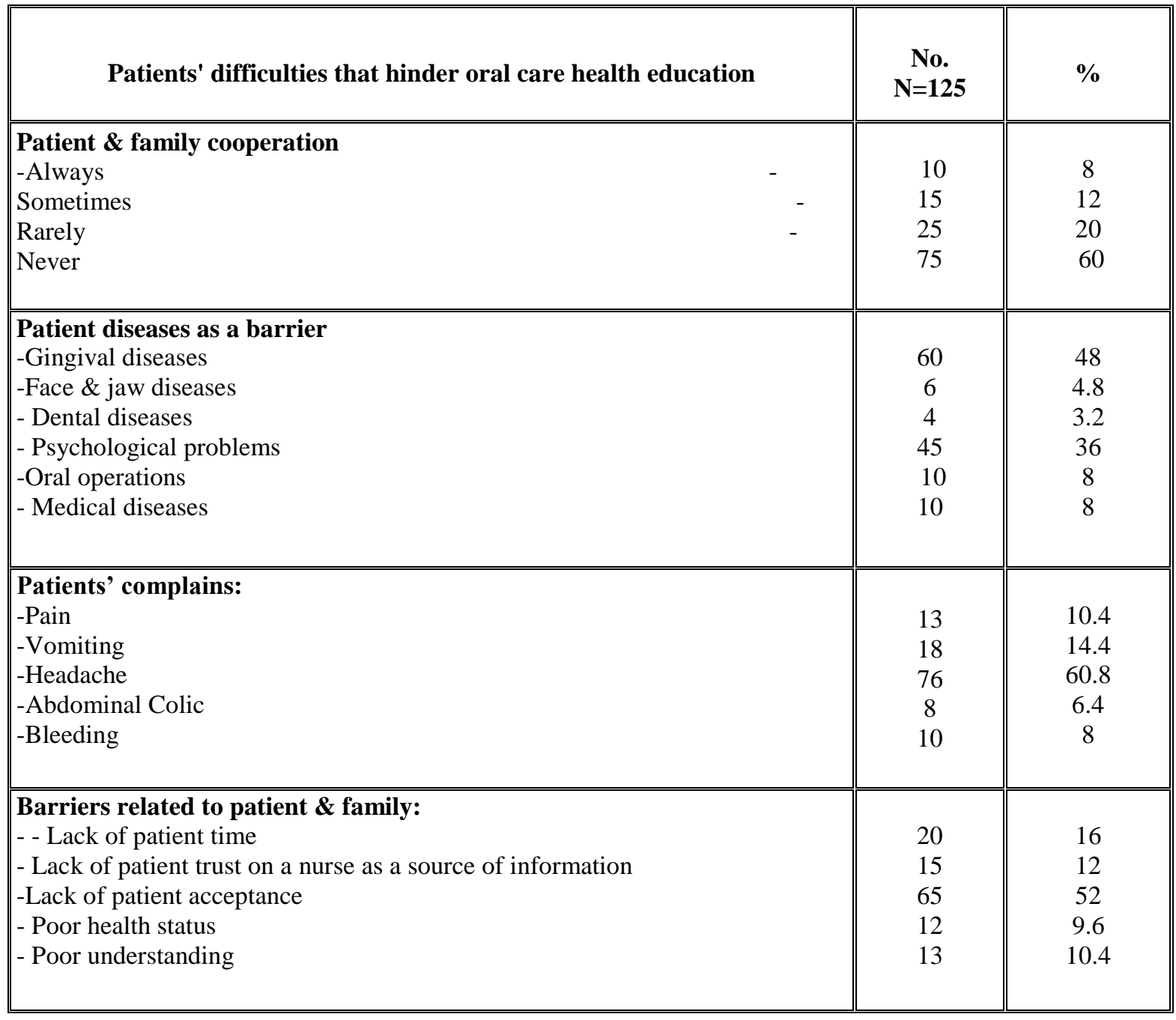


Table (6): Distribution of the subjects according to their difficulties in oral care health education related to health team and setting.

\begin{tabular}{|c|c|c|}
\hline $\begin{array}{c}\text { Health team \& setting difficulties that hinder } \\
\text { oral health education }\end{array}$ & $\begin{array}{c}\text { No. } \\
N=125\end{array}$ & $\%$ \\
\hline $\begin{array}{l}\text { Cooperation of health team: } \\
\text {-Always } \\
\text {-Sometimes } \\
\text {-Rarely } \\
\text {-Never }\end{array}$ & $\begin{array}{l}80 \\
10 \\
10 \\
25\end{array}$ & $\begin{array}{c}64 \\
8 \\
8 \\
20\end{array}$ \\
\hline $\begin{array}{l}\text { Presence of a suitable place } \\
\text {-Always } \\
\text {-Sometimes } \\
\text {-Rarely } \\
\text {-Never }\end{array}$ & $\begin{array}{l}6 \\
4 \\
45 \\
60\end{array}$ & $\begin{array}{l}4.8 \\
3.2 \\
36 \\
48\end{array}$ \\
\hline $\begin{array}{l}\text { Rules, routine \& polices -Always } \\
\text {-Sometimes } \\
\text {-Rarely } \\
\text {-Never }\end{array}$ & $\begin{array}{c}18 \\
89 \\
8\end{array}$ & $\begin{array}{c}4.4 \\
71.2 \\
6.4\end{array}$ \\
\hline $\begin{array}{l}\text { Availability of resources for health } \\
\text { education: } \\
\text {-Yes } \\
\text {-No } \\
\text { know }\end{array}$ & $\begin{array}{c}20 \\
102 \\
3\end{array}$ & $\begin{array}{c}16 \\
81.6 \\
2.4\end{array}$ \\
\hline $\begin{array}{l}\text { Barriers related to health team \& setting: } \\
\text {-Lack of time } \\
\begin{array}{l}\text { cooperation of health team } \\
\text {-Work overload }\end{array} \\
\text { facilities \& resources }\end{array}$ & $\begin{array}{l}15 \\
12 \\
85 \\
13\end{array}$ & $\begin{array}{c}12 \\
9.6 \\
68 \\
10.4\end{array}$ \\
\hline
\end{tabular}

Table (7): Nurses' difficulties in providing oral care health education in relation to their sex as presented by mean and stander deviation.

\begin{tabular}{|c|c|c|c|c|}
\hline Nurses' difficulties in oral health & \multicolumn{2}{|c|}{ Female $(n=102)$} & \multicolumn{2}{|c|}{ Male $(n=23)$} \\
\hline \multirow{3}{*}{ Conducting health education process } & $\overline{\mathbf{X}}$ & SD & $\overline{\mathbf{X}}$ & SD \\
\hline & 3.48 & 3.37 & 2.85 & 3.29 \\
\hline & \multicolumn{4}{|c|}{$\mathrm{T}=0.826$} \\
\hline \multirow{2}{*}{ Patients \& families } & 6.93 & 8.24 & 8.41 & 8.29 \\
\hline & \multicolumn{4}{|c|}{$\mathrm{P}=0.44$} \\
\hline \multirow{2}{*}{ Health team \& setting } & 72.2 & 8.04 & 71.69 & 8.10 \\
\hline & \multicolumn{4}{|c|}{$\mathrm{P}=0.392$} \\
\hline
\end{tabular}

*Significant relation at $\mathrm{P}$ level $<0.05$

Table (8): Nurses' difficulties in providing oral care health education in relation to their qualifications as presented by mean and stander deviation. 
Abd El Azize Th1. M. Ibrahim AF2"." Relationship betw ..."

\begin{tabular}{|c|c|c|c|c|c|c|}
\hline \multirow[t]{2}{*}{$\begin{array}{l}\text { Nurses' difficulties in oral } \\
\text { health education }\end{array}$} & \multicolumn{2}{|c|}{$\begin{array}{c}\text { Diploma } \\
(\mathrm{n}=85)\end{array}$} & \multicolumn{2}{|c|}{$\begin{array}{c}\text { Associate } \\
(\mathbf{n}=\mathbf{2 0})\end{array}$} & \multicolumn{2}{|c|}{$\begin{array}{c}\text { Bachelor } \\
(\mathbf{n}=\mathbf{2 0})\end{array}$} \\
\hline & $\overline{\mathbf{X}}$ & SD & $\overline{\mathbf{X}}$ & SD & $\overline{\mathbf{X}}$ & SD \\
\hline $\begin{array}{l}\text { Conducting health education } \\
\text { process }\end{array}$ & 42.6 & 2.7 & 30.4 & 4.0 & 23.8 & 3.4 \\
\hline ANOVA=F & \multicolumn{6}{|c|}{$\mathbf{F}=81.122 * *$} \\
\hline Health team \& setting & 20.7 & 5.9 & 15.6 & 2.4 & 13.0 & 3.6 \\
\hline ANOVA=F & \multicolumn{6}{|c|}{$\mathbf{F}=76.25 * * \quad P$ value $=0.00$} \\
\hline Patients \& families & 26.0 & 8.2 & 18.5 & 5.8 & 13.5 & 5.9 \\
\hline ANOVA $=F$ & \multicolumn{6}{|c|}{$P$ value $=0.00$} \\
\hline
\end{tabular}

Table (9): Distribution of mean and standard deviation of the study subjects according to rank of barriers in oral health education.

\begin{tabular}{|c|c|c|}
\hline Ranking of barriers & Mean \pm SD & $\begin{array}{c}\text { Median } \\
\text { (Min.-Max.) }\end{array}$ \\
\hline nurses themselves barriers & $6.84 \pm 2.361$ & $\begin{array}{c}3.00 \\
(1.00-10.00)\end{array}$ \\
\hline Patients \& families' barriers & $4.23 \pm 1.773$ & $\begin{array}{c}2.00 \\
(1.00-10.00)\end{array}$ \\
\hline Health team \& health setting barriers & $2.34 \pm 1.828$ & $\begin{array}{c}1.00 \\
(1.00-10.00)\end{array}$ \\
\hline
\end{tabular}

\section{Discussion}

Health education is directed towards improving health literacy and people's capacity to manage health problems. (Don Nutbeam 2006, Horowitz in 1995). Patients have the right to take decisions that may affect their health by attending health education sessions, where ensures the knowledge and skills related to their health. (Schou and Locker 1997)

Oral care health education in particular calls for active action from the patient. The lack of understanding around oral health, negatively affects both oral and overall health. However, oral health education still not obtains its essential value among clients, professionals and community. (Shay and Ship in 1995, Abd El Mohsen A, 2009)

It is very important to announce that the dental health education require a dental or oral health specialist who require broad knowledge and skills related to health education assessment and integrate it with different oral diseases.

The current study was held to determine the barriers encountered by nurses while providing oral care health education. Identifying these difficulties is a critical goal to overcome it and design suitable educational interventions for nurses.
The present findings for subjects' socio-demographic data revealed that the highest percentage of study subjects were in early twenties, females and have diploma degrees with 5-10 years of experience in oral health care. This characteristic clarifies that the majority of the subjects were young with limited qualifications and experience that can be an essential barrier among them that may hinders the oral health education activities.

This is supported by the National examining board for dental nurses in 2008 that mentioned that extended clinical duties, years of experience, high qualifications and age for dental nurses to get further well career opportunities and manage dental work activities. Providing training and qualifications opportunities for dental nurses in oral health education is important to develop further knowledge and new skills in extended clinical duties. The dental and oral health nurse has to be succeeded, professional and competent in addressing the different patient learning needs.

While assessing the need for oral health education, the majority of the study subjects complained that; they had no time to estimate patients learning needs 
and communicate health information. There was no specific person had a responsibility to provide oral care health education. Moreover, they didn't know to take patient approval before teaching and perceived that they had limited and no knowledge about health education assessment. Furthermore, the majority of the subjects stated that the most difficult diseases to be discussed or prepared for oral health education are dental caries, gingival diseases, oral cancer, plaque and over all hygienic care of oral health.

Nurses complains are not consistent with the twostage team approach to dental health education recommended by Daly, Watt, Batchelor and Treasure E T., in 2002, when they state that dental professional should be involved in assessing their clients' health education needs, and where appropriate, providing opportunistic advice and support. Oral health staff have an obligation to provide information about oral diseases and their prevention, oral health education assessment is the cornerstone of whole health education activities and dental nurses must find time and trained him/her on how to assess patient learning needs especially in oral care, that mainly manage by health teaching.

Oral health education is often neglected by health care providers. Lack of well-defined role expectations and lack of knowledge are frequently cited by nurses as difficulties to provide oral health education. Nurses are in a unique position to contribute in the improvement of her/his knowledge, skills and attitudes. Therefore, a well planned program for oral health education is encouraged for oral health care professionals, because the oral health education is an important part of total plan of patient care. (Blevins JY 2011, Kay and Locker 1996, World Health Organization 2013, Daly, Watt, Batchelor and Treasure 2002).

Almost all of subjects complained that they didn't know how to plan for oral health education or to write oral health educational objectives. They found difficulties to use language in dental health and there was no enough time to prepare the oral teaching content. Furthermore, they didn't know the types of or how to prepare educational audiovisuals. Therefore, it is a big problem of lacking in knowledge and skills in oral and dental health education activities.

Contrarily, the dental profession has had a longstanding concern with the health education and promotion for oral diseases. It is essential that oral health promoters develop an improved understanding of oral health messages, planning for how to effectively improve oral health and use evidence based practice in supportive media environment. (Kay EJ, Locker D in 1996, Schou L, Locker D in 1997)

Valley in 2003 supported what perceived by the study subjects. He mentioned that the lack of time and poor preparation for patient education content was a frequent barrier for all nurses in all nursing fields. Poor educational preparation of nurses to be competent planners and teachers is one result of poor quality of professional practice in patient education (Redman1976, Abd El Mohsen A, 2009). In the same aspect, Fathy A in 2006 mentioned that one of the most important steps in health education is the appropriate plan, selection of instructional media, formulating of educational objectives of teaching content which are lacked with most of nurses.

Regarding implementation of oral health education, the majority of nurses reported that they didn't know how to provide clarifications, examples and motivation for patients. Exactly all of the nurses have no knowledge about methods of teaching in oral health education. Thus, the nurses have great hindering factors for conducting oral health education interventions.

This is in the line with Department of Health and Human Services, Public Health Service Centers for Disease Control and Prevention in 2003 and Locker D in 1997 reported that; the implementation of oral health education represents a unique opportunity for early prevention of both oral and general health problems. Health professionals found it is difficult to stimulate the interest of patient by tailoring the health message, especially in oral health units, and provide appropriate educational interventions. Also, Abd El Mohsen in 2009 and Novello AC et al in 1992 stressed on that the inability to prepare, select, conduct the teaching activities and develop instructional aides for patient are considered a great barrier for transferring of health messages and require attention from nursing education. Health and education go hand in hand: one cannot exist without the other.

On the other hand, dental health educator has a responsibility to provide supportive environments with appropriate teaching, and practices to help patients and public. This teaching includes understanding of good oral hygiene and healthy eating behaviors; the importance of fluorides and fluoridation, dental sealants, accessing dental care on a regular basis; the impact of tobacco use on the mouth; risks of oral piercing; HPV and oral cancer; how tooth decay forms; and other oral health topics. Oral health education as a part of health education may contribute to help patients in informed decision making about oral health.

For the evaluation and documentation of oral health education, almost all of the subjects stated that they didn't evaluate patients' learning and teaching effectiveness. They found a difficulty in formulating questions regarding dental diseases. Also, they mentioned that there was no specific document or enough time for recording oral health education activities. It is clear that there is no specific system for evaluating or documenting oral health education activities in dental units which is a huge missing aspect in health care services. 


\section{Abd El Azize Th1. M. Ibrahim AF2"." Relationship betw ..."}

This was supported by Vazquez in 1995 and Bertness J, Holt K in 2009 who mentioned that the process of evaluation for patient learning is feared and misunderstood by many nurses. Mainly, the effectiveness of oral health education activities has seldom been evaluated. If the evaluation is carried out in a constructive and systematic way and results were taken into account, it can be a very useful mean of assessing achievements for real health improvement. Evaluation in oral health is a valuable step because prevention is the key to control dental disease, that carries and periodontal disease are largely preventable through learning personal lifelong healthy behaviors.

But, health educator has responsibilities for evaluating, charting patients' education outcome. Training on conducting evaluation and recording of patient oral health education are the core elements of dental nurse traits; she/he should identify weak and strength points of teaching activities and try to modify and follow up the patient awareness progress. This is essentially in dental and oral health. Because oral health problems can be managed and prevented by health teaching and personal self activities as discussed by Akbulut Y., Kurter E in 2007 and Bertness J, Holt K in 2009.

Respectively to the barriers regarding patients' characteristics as perceived by the study subjects at oral health care units, the majority of them mentioned that health beliefs or thoughts and patients' level of education were strong factors that hindered oral health education, followed by patients' past experience, religion and language. The alteration of attitudes, beliefs, education and language in order to promote oral health via is an extremely heterogeneous. Lack of routine dental care, Tooth decay dental pain, poor nutrition, and dysfunctional speech, as well as a lack of concentration, poor appearance, low self-esteem and patients' oral health practices may also, be a challenge for health educator to overcome these obstacles.

Health disparities are commonly associated with populations whose access to oral health education services is compromised by poverty, income level, limited education or language skills, race/ethnicity, geographic isolation, religion, age, gender, disability, or an existing medical condition. Adults' education and lacking language skills or reading competence may be a barrier for dental and oral education. Researchers continue to see disparities in the burden of oral diseases and oral health teaching. For example, patients with low education and false health belief, have multiple oral health problems than whom with high education level. Challenges remain in eliminating inequalities in oral health field and receipt of preventive measures. (Department of Health and Human Services, Public Health Service Centers for Disease Control and Prevention 2003, Centers for Disease Control and Prevention,
National Center for Chronic Disease Prevention and Health Promotion 2011, Shay K, Ship JA 1995).

In relation to other hinders that faced nurses in oral health education related to the patient and family, they complained of un-cooperation from patients and their families for health communication. The most common patients' health problems that may hinder oral health teaching were; gingival inflammation, headache and psychological problems. Also, Lack of patients' trust on a nurse's information was another barrier.

Graziani C., Rosenthal M., Diamond J., in 1999 discussed that the patients have several misperceptions, fears, culture diversity, false beliefs and inconsideration and unawareness about the value of health literacy. Hmud R. and Walsh in 2009 , reported that fear of pain have been linked strongly to the development of dental anxiety and to avoidance of dental treatment. Even at extreme levels of oral clinical morbidity many patients still belief themselves to be in good oral health. While lacking of oral health knowledge, awareness of health education importance, costly dental health treatment and non feasibility of oral education interventions in low and middle income countries, lead to several complications for oral health with individuals and communities. All these factors may be hider their cooperation and foster their misunderstanding in the field of oral health education.

Furthermore, each patient has a different capacity to learn, varying in dimensions of physical, emotional, and cognitive readiness. When patient suffers from acute symptoms as: pain, vomiting, gingival inflammation and gum sore or any other general complain, at this moment patient is not ready for learning. So, patients have several factors hindering his/her oral health education activities. (Awasthi SH, Bhandari M. 2006) Therefore, it is a challenge for dental nurses to use proper communication, build of effective nurse patient relationship, and persuade the patient to gain information, skills and attitudes. It is the responsibility of the health care system to ensure that the delivery of care is consistent with the patient's values and not a result of miscommunication or cultural stereotyping. (Volandes A., Ariza M., abbo E., Paasche-orlow M 2008)

Oral health staff themselves and health setting, also, can be a source of oral health education barriers. About all of the subjects reported that there was no suitable place to conduct health education. Work load and health setting routine and polices are common barriers to the implementation of oral care health education activities. Oral health setting has a great role in promoting and enhancing the oral health teaching among staff and in between patients. Incongruence with subjects complains, some researchers reported that oral health setting, including learning climate and organizing of place of 
teaching, overarching theme should enhance an individualized creation and support well informed decision making regarding patients' own health.( Bergström H., Elinder L.S. Wihlman, U. 2014, Daly B, Watt R G, Batchelor P and Treasure E T. 2002 ). In Egypt, there are many obstacles that impair the advancement of professional nursing which in turn may inhibit goal acquisition of total care. These obstacles include: supply and demand for nurses, education level of nurses, long hours, poor working conditions, difficult routine and low wages. Egypt suffers from a severe shortage in the number of nurses in hospitals and public clinics. There are 276 nurses for every 100,000 people" that of course explains why working load of nurses in Egypt is increased. Hence, it is important to work across agencies and sectors to develop a range of complementary approaches. However, oral health units need to work in partnership with other professional bodies to ensure that the way of oral health education is delivered in a setting reaches a consistent standard. Also, it is essential to develop national occupational standards for oral health promotion (Rashdan T., 2007, Department of Health 2005). Moreover, Fathy in 2006 stressed that there is no special or appropriate place for patient teaching and the unavailability of equipment, facilities and instructional aides to be used in teaching at clinical practice. So, the Department of Oral Health and dental care professionals rightly recognizes that oral health should be considered as part of general health, and that 'health education helps, but is not enough without preparation, plan, place, materials and cooperation.

When comparing between male and female subjects in relation to the encountered barriers in oral health education, there was no statistical significance difference between both genders regarding all revealed health education barriers, Gender differences in the nursing profession still need extensive research, especially in oral health care. In the line with this result, Lapp in 2003 reported that men choose to go into the nursing profession are similar to those cited by women who go into the field: Male nurses started to understand themselves to go into a highly female profession. This point of view is supported by the current results, because male nurses faced the oral care health education barriers, approximately as female nurses.

Dissimilar to this view, the results of Freeman R., and Williams Mc.W, W in 2008, who concluded that differences in communication and working styles exist between male and female dental nursing students. The female compared with the male students felt a disadvantage when requesting and obtaining nursing assistance. Women nurse students found it harder to request nursing support, this suggested that gender acted indirectly as a factor in gaining chair-side advice. Therefore similarities and differences related to gender are vary and need more investigation

Respectively, the level of nurses' education and qualification is considered as a greet factor to determine the oral health care barriers that face health professionals. As seen in the present results; the diploma nurses confront more barriers and difficulties than associate and bachelor degrees when comparing the three levels of nursing qualifications. So, oral health education training could be provided, both as part of the undergraduate curriculum and as part of continuing professional development, to promote a better understanding of counseling skills and educative techniques in dental health education.

Therefore, Nurses should be educationally well prepared to be proper health educators. They have been challenged to become more competent to create and solve problems and dilemmas that arise during patient education process. (Smith H., Pressman H., 2010). A baccalaureate program is for an advanced degree and offers more breadth and depth of study in nursing. A diploma or associate's degree often work in the field for a period of time, and then return to school to acquire a baccalaureate nursing degree to enhance their skills. Baccalaureate programs offer more advanced education in areas that support critical thinking, clinical reasoning, and analytical skills; prepare nurses for a broader scope of practice; further professional development; and facilitate understanding of complex issues affecting healthcare delivery. (National Advisory Council of Nurse Education and Practice 2010)

Finally, the study subjects ranked the difficulties in conducting the oral health education process as the first and major problem encountered them. It is expected findings because a high proportion of these nurses had inadequate knowledge about oral health, particularly in the domain of the indicators of a healthy mouth' and in preparing or conducting oral health messages. This in line with Milde and Heim in 1991 who reported that nurses perceived themselves as inadequately prepared to provide health education and the nursing administrators perceive undergraduate nursing students at a lower competency level in this aspect. Also, Levin in 2006 and Kay EJ, Locker D in 1996, mentioned that dental nurses faced several problems and barriers in oral health education related to a serious lacking in knowledge and practicing health education activities. The emphasis throughout is on the advice available to the dental team on how to teach patients to change their behavior, rather than on shifts in the scientific basis of the content of that advice.

\section{Conclusion}

Oral diseases are major health concern affecting almost every person in the world. Most oral diseases are preventable by oral health education which can 
then reduce pain, suffering, and health care expenses. The current study reveals that, a high proportion of nurses in oral health care units confront a multiple difficulties related to assessment, planning, implementation, evaluation and documentation of oral health education activities and these barriers mainly encountered diploma nurses than associate or baccalaureate ones.

\section{Recommendations and further studies:}

Nurses as health educators, must facilitate the educational process for patient, family and society. Experienced dental nurses are in demand for a wide range of job opportunities, creativity and critical thinking skills to make decisions in their work and should be competent in oral health education activities. Efforts are needed because oral diseases still affect all dimensions of people life. Collaboration and cooperation between oral health and other disciplines is an urgent issue. Furthermore, a strategic plan for oral health education training must be established to be used among nurses. The present study provided a view of further studies:

Replication of the current study with dental patients themselves to identify the difficulties from their perspectives.

Develop an oral health education strategic plan for nurses to help them; managing any obstacles may face them in health education.

Use health education models as a guide for training nurses in oral health education.

Survey for all oral health clinical areas in Egypt to determine the resources and facilities for oral health education.

Collaboration, guidance and support for all other disciplines to manage common oral health education barriers among dental professionals.

\section{References:}

[1] Abd El Mohsen A. Barriers encountered by undergraduate nursing students while providing health education for patients. Unpublished Master Thesis. Faculty of Nursing, University of Alexandria. 2009, 3412.

[2] Akbulut Y., Kurter E. Health Education through Information and Communication Technologies for k-8 Students: Cell biology, Microbiology, Immunology and Microscopy, Journal of Theoretical and Applied Information Technology. 2007:1-12 Available at: http://jatit.org/volumes/researchpapers/Vol3No2/6vol3.pdf Accessed June, 2013.

[3] Awasthi SH, Bhandari M. Identification and Prioritization of Barriers to Quality Performance in Medical Education and Patient
Care, Medical University in India, Kamla-Raj 2006; 13(2): 157-162.

[4] Bergström H., Elinder L.S. Wihlman U. Barriers and facilitators in health education for adults with intellectual disabilities-a qualitative study. Oxford Journals, 2014. Available at http://her.oxfordjournals.org/content/early/201 4/01/07/her.cyt111.full.pdf+html Accessed January 2014

[5] Bertness J, Holt K, eds. Promoting Oral Health in Schools: A Resource Guide - April 2009.

Washington, DC: National Maternal and Child Health Oral Health Resource Center; 2009.

Available at:

http://www.mchoralhealth.org/PDFs/ResGuide SchoolOH.pdf. Accessed January, 2014.

[6] Blevins JY., Oral Health Care for Hospitalized Children. PEDIATRIC NURSING, Continuing Nursing Education 2011; 37(5) 229-235

[7] Centers for Disease Control and Prevention, National Center for Chronic Disease Prevention and Health Promotion. Oral Health Program Strategic Plan for 2011-2014. Centers for Disease Control and Prevention; 2011 Available at: ww.cdc.gov/Oral Health/ Accessed Jane, 2014.

[8] Daly B, Watt R G, Batchelor P and Treasure E T. Essential Dental Public Health. Oxford: Oxford University Press, 2002.

[9] Department of Health and Human Services, Public Health Service Centers for Disease Control and Prevention. A National Call to Action to Promote Oral Health; NIH Publication No. 03-5303; 2003 Available at: www.nidcr.nih.gov Accessed January, 2014.

[10] Department of Health. Choosing Better Oral Health: An Oral Health Plan for England. London: department of Health, 2005.

[11] Fathy A. Development of patient health education model to guide undergraduate nursing students. Unpublished MSN Thesis. Alexandria: University of Alexandria, Faculty of Nursing 2006: 23-37.

[12] Freeman R., and Williams Mc.W, W Dental students and nurses: Investigating gender differences in communication and working styles. Newcastle University, 2008

[13] Graziani C., Rosenthal M. and Diamond J. Diabetes Education Program Use and Patientperceived Barriers to Attendance. Fam Med., 1999; 31(5):358-63

[14] Hmud R., Walsh LJ. Dental anxiety: causes, complications and management approaches. 
Journal of Minimum Intervention in Dentistry 2009; 2 (1) 67-78.

[15] Horowitz AM. The public's oral health: the gaps between what we know and what we practice. Adv Dent Res 1995; 9:91-5.

[16] Kay EJ, Locker D. Is dental health education effective? A systematic review of current evidence. Community Dent Oral Epidemiol 1996; 24:231-5.

[17] Lapp, R. (2004). Male nurses move beyond stereotypes. Retrieved May 19, 2004, available at:

http://www.goshen.edu/news/bulletin/03sept/0 3 male.php Accessed March 2014

[18] Levin M. Language as a barrier to care for Xhosa-speaking patients at a South African pediatric teaching hospital 2006: (96) 10761079.

Available

at: http://www.samj.org.za/index.php/samj/article/ viewFile/1309/742 Accessed March 2014.

[19] Mayeaux EJ, Murphy PW, Arnold C, Davis TC, Jackson RH, Sentell T. Improving patient education for patients with low literacy skills. American Family Physician 1996, 53(1):20511

[20] Milde K, Heim L. Competence to provide health education: perception of nursing students and faculty. Journal of Nursing Education 1991; 30.

[21] National Advisory Council of Nurse Education and Practice. Addressing New Challenges Facing Nursing Education: Solutions for a Transforming Healthcare Environment. 8th Annual Report. to the Secretary of the U.S. Department of Health and Human Services and the U.S. Congress. Rockville, MD: Health Resources and Services Administration, U.S. Department of Health and Human Services. 2010; 6-15

[22] National examining board for dental nurses; certificate in special care dental nursing. NEBDN, 2008 Available at: http://www.nebdn.org/pdf/SCNProspectus.pdf Accessed January, 2014.

[23] Novello AC, Degraw C, Kleinman DV. Healthy children ready to learn: an essential collaboration between health and education. Public Health Rep. 1992; 107(1):3-15. http://passthrough.fw-

notify.net/download/771561/http://www.ncbi.n lm.nih.gov/pmc/articles/PMC1403595/pdf/pub healthrep00075-0005.pdf Accessed January, 2014.

[24] Nutbeam D. Health literacy as a public health goal: a challenge for contemporary health education and communication strategies into the 21st century, Oxford Journals, 2006; 15(3) 259-267.

[25] Oral health: Oral health through health promoting schools. World Health Organization. 2013. Available at: http://www.who.int/oral_health/action/groups/ en/. Accessed June, 2013.

[26] Smith H., Pressman H. Training Nurses in Patient Communication 1st ed. Central Coast Children's Foundation, Inc., 2010. available at:

http://patientprovidercommunication.org/pdf/9. pdf Accessed March 2014

[27] Schou L, Locker D. Principles of oral health promotion. In: Pine CM, editor. Community oral health. Oxford: Reed Educational \& Professional Publishing Ltd; 1997. 177-87.

[28] Shay K, Ship JA. The importance of oral health in the older patient. Journal of the American Geriatrics Society1995, 43(12):1414-22

[29] The art of nursing. School of Health Science, International Journal of Nursing Studies, 1999. 36(5):379-85 available at: http://www.sciencedirect.com/science/article/p ii/S0020748999000371

[30] Valley H. Nurses Identify Barriers to Teaching Patients about Their Medications. Institute for Safe Medication Practices, 2003. Available at: http://www.ismp.org/ Accessed January, 2014.

[31] Vazquez L. Chess Evaluation of health education programmes, Community Health Education support service. 1995; 7(15):5.

[32] Volandes A., Ariza M., abbo E., Paasche-orlow M. Overcoming Educational Barriers for Advance Care Planning in Latinos with Video Images. Journal of palliative medicine, 2008; 11(5):700-6 